\title{
SISTEM INFORMASI AKUNTANSI DALAM PENYAJIAN AUDIT FINANCIAL REPORT DENGAN MENGGUNAKAN COMPUTER ASSISTED AUDIT TECHNIQUES (CAATS)
}

\author{
Nur Azizah ${ }^{1}$; Ferry Sudarto ${ }^{2}$ \\ 1,2 Jurusan Teknik Informatika, STMIK Raharja \\ JIn. Jendral Sudirman No. 40, Modern Cikoko, Tangerang \\ nurazizah@faculty.raharja.ac.id; ferry@faculty.raharja.ac.id
}

\begin{abstract}
The use of computerized technology in the current globalization era has become more rapid therefore assisting all activities in all fields, especially in the financial audit report in an accounting information system. Many problems were encountered with the auditors in conducting audits using conventional methods in an electronic data processing environment. However, these constraints are often ignored and do not get serious attention even by the auditors themselves. Inefficiencies resulted is often not oblivious. Therefore, constraints that occurred can be solved with a variety of ways, including the usage of Computer Assisted Audit Technique (CAATs) through a test data approach and Parallel Test Facility (PTF).
\end{abstract}

Keywords: audit financial report, CATTs, accounting information system

\begin{abstract}
ABSTRAK
Penggunaan teknologi komputerisasi di era globalisasi saat ini sangat pesat sehingga dapat memudahkan semua kegiatan di segala bidang khususnya dalam kegiatan audit financial report pada sistem informasi akuntansi. Banyak kendala yang dijumpai auditor dalam melakukan audit dengan metode konvensional dalam lingkungan pemrosesan data elektronik. Namun seringkali kendala tersebut cenderung diabaikan dan kurang mendapat perhatian serius bahkan oleh si auditor sendiri. Akibatnya terjadi inefisiensi yang tidak disadari. Oleh karena itu kendala yang terjadi dapat diselesaikan dengan berbagai cara, antara lain dengan menggunakan Computer Assisted Audit Technique (CAATs) melalui pendekatan data uji dan Parallel Test Facility (PTF).
\end{abstract}

Kata kunci: audit financial report, CATTs, sistem informasi akuntansi

\section{PENDAHULUAN}

Audit merupakan sebuah kegiatan yang melakukan pemeriksaan untuk menilai dan mengevaluasi sebuah aktivitas atau objek seperti implementasi pengendalian internal pada sistem informasi akuntansi, yang pekerjaannya ditentukan oleh manajemen atau proses fungsi akuntansi yang membutuhkan improvement. Proses auditing menjadi sangat rapi di Amerika Serikat, khususnya pada bidang professional accounting association. Akan tetapi, baik profesi audit internal maupun eksternal harus secara terus menerus bekerja keras untuk meningkatkan dan memperluas teknik karena profesi tersebut akan menjadi tidak mampu untuk mengatasi perkembangan dalam teknologi informasi dan adanya tuntutan yang semakin meningkat oleh para pemakai informasi akuntansi (Cangemi, M.P., dan Singleton, T., 2002). Meskipun berbagai macam tipe audit dilaksanakan, sebagian besar audit menekankan pada sistem informasi akuntansi dalam suatu organisasi dan pencatatan keuangan serta pelaksanaan operasi organisasi yang efektif dan efisien. Banyak kendala yang dijumpai auditor dalam melakukan audit dengan metode konvensional dalam lingkungan pemrosesan data elektronik. Namun, seringkali kendala tersebut cenderung diabaikan dan kurang mendapat perhatian serius, bahkan oleh si auditor sendiri. Akibatnya, terjadi inefisiensi yang tidak disadari.

Seringkali dalam lingkungan Pemrosesan Data Elektronik, volume dan kompleksitas data yang harus diperiksa jauh lebih besar dibandingkan dengan kemampuan auditor. Akhirnya, jalan pintas pun sering dilakukan, misalnya menggunakan sampling secara acak tanpa memperhatikan apakah sampling tersebut cukup mewakili atau tidak. Juga kadang jika melakukan substantive test atas data hanya didasarkan pada print-out dengan cara manual serta audit trail yang tidak terdeteksi karena sistem operasi telah terkomputerisasi. Pada akhirnya, kesimpulan audit dapat dipastikan tidak akan memadai, yang akhirnya opini terhadap laporan keuangan secara keseluruhan tidak memiliki dasar yang memadai dan gilirannya berdampak pada terciptanya informasi yang menyesatkan.

Sebenarnya konsep dan prinsip auditing, baik di lingkungan manual dan lingkungan sistem informasi yang berbasis komputer tidak berubah. Yang berubah adalah metode dan tekniknya saja. Beberapa teknik dan metode tersebut berbeda karena antara lain disebabkan oleh (1) Otomatisasi, yaitu seluruh proses di dalam pemrosesan data elektronik, mulai dari input hingga output cenderung secara otomatis, bentuk penggunaan dan jumlah kertas cenderung minimal, bahkan seringkali tidak ada (paperless office) sehingga untuk penelusuran dokumen (tracing) audit berkurang dibandingkan sistem manual yang banyak menggunakan dokumen dan kertas; (2) Keterkaitan aktivitas yang berhubungan dengan catatan-catatan yang kurang terjaga; (3) Dengan sistem on line mengakibatkan output seringkali tidak tercetak; (4) "Audit Around Computer" yang mengabaikan sistem komputer, tetapi yang dilihat atau yang diuji adalah input dan output; (5) "Audit Through Computer" menggunakan bantuan komputer (atau software) untuk mengaudit (Hall, J.A., 2001).

Jika pelaksanaan audit di sistem informasi berbasis komputer dilakukan secara konvensional terhadap lingkungan PDE seperti dalam sistem manual, maka cenderung tidak 
menghasilkan hasil yang memuaskan, baik oleh klien maupun auditor sendiri, bahkan cenderung tidak efisien dan tidak terarah. Untuk itu, dalam pengembangan sistem informasi akuntansi berbasis komputer dalam memudahkan pengendalian dan penelusuran audit, khususnya financial report dapat menggunakan berbagai jenis sistem penggunaan komputer. Dalam audit disebut dengan istilah Teknik Audit Berbantuan Komputer (TABK), sedangkan dalam Bahasa Inggris disebut Computer Assisted Audit Techniques (CAATs). Pendekatan audit dengan komputer sebenarnya adalah hanya merupakan teknik pelaksanaan pengumpulan/evaluasi bukti audit. Tujuan audit itu sendiri tetap tidak berubah. Dalam audit financial report dengan CAATs, audit dilaksanakan terhadap sistem akuntansi berbasis komputer, yang ruang lingkup dan tujuannya sebenarnya tetap, yaitu memberikan opini atas fairness dan kesesuaian sistem akuntansi dengan standar akuntansi keuangan (ISCA, 2005).

Penggunaan komputer sebagai alat bantu kegiatan audit (computer assisted audit) dilakukan dalam berbagai cara, yaitu antara lain menggunakan test deck, dengan Integrated Test Facility (ITF), Parallel Test Facility (PTF) atau parallel simulation, dengan paket software (generalized atau specialized audit software), dengan system tagging and tracing, dan job analysis. Metode berbasis TI dalam audit selalu berkembang sejalan dengan perkembangan teknologi. Teknologi audit tidak hanya tunggal, melainkan terdapat beragam alat dan teknik yang terus berkembang yang dapat digunakan secara memadai untuk mencapai tujuan-tujuan audit. Beberapa teknologi membutuhkan biaya besar, yang lain dapat diterapkan dengan biaya relatif kecil. Beberapa memerlukan kemampuan teknis auditor, akan tetapi kecenderungan yang ada ialah bahwa biaya software makin murah dan makin user friendly. Pada sisi lain, para auditor juga makin terlatih di bidang teknologi informasi (Romney, M.B., dan Steinbart, P.J., 2005).

Dengan berkembang pesatnya teknologi sistem informasi akuntansi untuk menyiapkan audit financial report yang up to date, akurat dan relevan, guna memberikan opini atas fairness dan kesesusaian sistem akuntansi berdasarkan standar akuntansi keuangan dengan menggunakan beragam alat atau teknik yang terdapat pada Computer Assisted Audit Techniques (CAATs), maka penulis membatasi ruang lingkup penggunaan komputer sebagai alat bantu kegiatan audit, yang dilakukan dengan cara menggunakan tesk deck, Parallel Test Facility (PTF) atau parallel simulation.

\section{HASIL DAN PEMBAHASAN}

\section{Pendekatan Data Uji}

Pendekatan data uji (test deck approach) merupakan pelaksanaan audit yang dilakukan dengan "using the auditor's data with client's software". Maksudnya adalah menguji sistem komputerisasi audit dengan menggunakan datanya auditor. Dalam hal ini, auditor harus membuat satu set data buatan (dummy data) untuk dipakai menguji apakah pengendalian interen telah dijalankan sesuai dengan yang seharusnya. Test data dibuat untuk tiap jenis transaksi yang akan diuji. Test data yang baik harus dirancang sedemikian rupa sehingga dapat mewakili semua kesalahan yang biasa terjadi. Makin sedikit datanya, makin komplit kemungkinan kesalahan yang dapat diuji akan memberikan kesempatan bagi auditor untuk memprediksi hasil uji cobanya dan menarik kesimpulan dari hasil evaluasi (Liang, D., F. Lin, and S. Wu., 2001).

Secara historis, metode data uji merupakan teknik pertama dalam audit dengan bantuan komputer. Meskipun sangat terbatas dalam memberikan kemampuan untuk menguji logika rinci program komputer bagi auditor, tetapi auditor akan dapat memahami spesifikasi sistem dan dapat memanfaatkan hal tersebut untuk menentukan apakah sistem bekerja atau tidak. Audit dengan test data ini sebenarnya sudah dianggap sebagai salah satu bentuk audit through the computer karena tujuan digunakannya test data ini adalah untuk dapat mengetahui apakah program yang dites sudah berjalan baik atau sesuai dengan spesifikasi. Sistem test deck pada hakekatnya adalah "simulated test data system", yang dimaksudkan untuk mengecek program tanpa harus mengikuti logika dari flowchart maupun membaca syntax (listing code) program. Menggunakan data uji tujuannya adalah untuk evaluasi kemampuan software audit dalam menangani berbagai jenis transaksi, atau dengan kata lain untuk menentukan apakah program komputer audit telah dilengkapi dengan pengendalian interen sehingga dapat menangani dengan benar transaksi yang sah ataupun yang tidak sah (tanpa harus membaca listing program atau program flowchart nya).

Cara yang dilakukan auditor dalam pelaksanaan audit dengan metode data uji adalah auditor men-generate dummy data, kemudian diproses dengan sistem aplikasi dan komputer yang ada diaudit. Data uji yang dibuat auditor harus mencakup seluruh kemungkinan transaksi yang tidak sah atau salah agar dapat ditentukan apakah program komputer yang diuji bereaksi dengan tepat terhadap berbagai kesalahan, dengan cara memeriksa daftar kesalahan dan perincian keluaran yang dihasilkan dari data pengujian. Data uji biasanya sengaja dibuat salah oleh auditor dan ia telah memperkirakan bahwa seharusnya komputer akan mendeteksi kesalahan itu. Jika ternyata pada expected result yang ia perhitungkan ternyata tidak terjadi, maka berarti ada sesuatu yang salah pada program aplikasi.

Teknik uji digunakan dalam pelaksanaan audit dengan memasukkan data ke sistem komputer klien dan membandingkan hasil yang diperoleh dengan hasil yang ditentukan sebelumnya (designed/expected result) (Gondodiyoto, S., 2007). Berikut ini dapat digambarkan sistem data data uji dalam CAATs (Gambar 1) (Gondodiyoto, S., 2007).

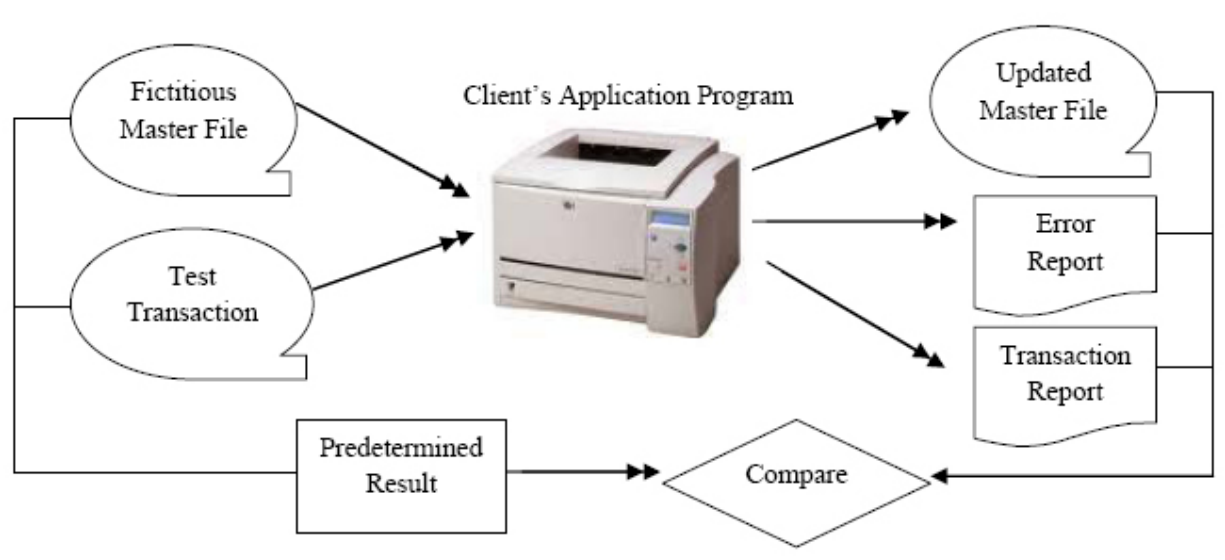

Gambar 1 Sistem Data Uji 
Dari Gambar 1, maka dapat disederhanakan menjadi:

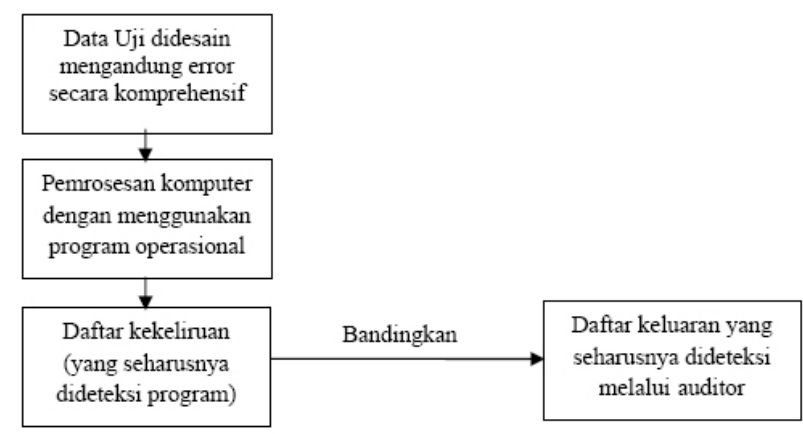

Gambar 2 Sistem Pendekatan Data Uji
Pada Gambar 1 dan 2, terlihat bahwa (1) Data uji harus mencakup seluruh kondisi yang diinginkan oleh auditor, baik data yang sah maupun data yang tidak sah (error); (2) Program yang diuji dengan data uji auditor harus sama seperti yang digunakan untuk operasional sepanjang tahun oleh klien (bukan program "palsu"); (3) Data uji harus segera dihapus oleh file klien segera setelah tes selesai, dengan maksud agar file sistem tidak terkontaminasi oleh data uji (bukan data transaksi sebenarnya); (4) Pelaksanaan data uji harus menjamin bahwa data uji tidak mempengaruhi file data sesungguhnya, dan akan ironis jika suatu prosedur audit yang dirancang untuk mendeteksi kekeliruan justru membawa kekeliruan. Hal ini membutuhkan koordinasi antara auditor dan karyawan komputer; (5) Auditor harus menjalankan pengendalian yang ketat. Auditor harus mengamati pemrosesan yang dilakukan oleh operator komputer. Jika pengujian selesai, maka auditor harus segera mendapatkan output tercetak. Kelebihan dan kelemahan sistem data uji dapat dilihat pada Tabel 1 (Wilkinson, J.W., 2004).

Tabel 1 Kelebihan dan Kelemahan Sistem Data Uji

\begin{tabular}{|c|c|c|}
\hline No & Kelebihan & Kelemahan \\
\hline 1 & Perform validity checks & $\begin{array}{l}\text { Limited by the auditor's imagination, maksudnya adalah } \\
\text { keberhasilan tes sangat bergantung dari kemampuan } \\
\text { auditor dalam memahami potensi error yang mungkin } \\
\text { dapat terjadi dan bagaimana ia membuat dummy } \\
\text { data untuk menilai apakah software yang diuji telah } \\
\text { dilengkapi validasi (kemampuan mendeteksi) hal itu. }\end{array}$ \\
\hline 2 & Perform limited and reasonableness checks & $\begin{array}{l}\text { Sulit to estabilish that the program being tested is the } \\
\text { one the client regularly uses karena sistem saja client } \\
\text { memiliki software ganda. Artinya, jika diuji klien } \\
\text { member software yang benar, tetapi sesungguhnya dalam } \\
\text { operasi sehari-hari klien memakai software yang lain } \\
\text { (yang salah atau yang menguntungkan perusahaannya). }\end{array}$ \\
\hline 3 & $\begin{array}{l}\text { Attempt to process an improperly authorized } \\
\text { transaction }\end{array}$ & $\begin{array}{l}\text { Dalam menggunakan teknik data uji harus dijaga agar } \\
\text { dummy data yang dibuat tidak "mengotori" data yang } \\
\text { sebenarnya (make sure that the test data doesn't affect } \\
\text { client's real data). }\end{array}$ \\
\hline 4 & $\begin{array}{l}\text { Insert characters in field that cause an } \\
\text { overflow condition }\end{array}$ & $\begin{array}{l}\text { Data uji sistem sangat mahal, pengembangannya } \\
\text { memerlukan banyak waktu, dan program yang diuji } \\
\text { ternyata mungkin diganti/diubah/bukan yang sebenarnya } \\
\text { sehingga hasil yang diperoleh cepat using atau tidak } \\
\text { tepat sasaran. }\end{array}$ \\
\hline 5 & Input an field with negative sign & $\begin{array}{l}\text { Bagi auditor pemula, mungkin sulit untuk mendeteksi } \\
\text { kecurangan yang dilakukan oleh operator sistem yang } \\
\text { ahli menukar program. }\end{array}$ \\
\hline 6 & $\begin{array}{l}\text { Perform numeric, alphabetic, and special } \\
\text { character checks }\end{array}$ & $\begin{array}{l}\text { Teknik tersebut sifatnya statis karena berfokus pada } \\
\text { titik waktu tertentu dan tidak memberikan hasil yang } \\
\text { berkesinambungan. }\end{array}$ \\
\hline 7 & & $\begin{array}{l}\text { Teknik ini berfokus pada program individual (program } \\
\text { tertentu yang diuji saja) dan cenderung tidak menguji } \\
\text { secara komprehensif atas keseluruhan rangkaian sistem } \\
\text { pemrosesan transaksi. }\end{array}$ \\
\hline 8 & & $\begin{array}{l}\text { Pada online processing system, cara ini tidak mudah } \\
\text { digunakan karena data uji dapat terkontaminasi dengan } \\
\text { data hidup (real data) file online. }\end{array}$ \\
\hline 9 & & $\begin{array}{l}\text { Sulit untuk membuat dat uji yang dapat meliputi seluruh } \\
\text { kemungkinan. }\end{array}$ \\
\hline 10 & & $\begin{array}{l}\text { Auditor tidak dapat mengetahui apakah program yang } \\
\text { dipakai pada saat ujicoba adalah program yang benar- } \\
\text { benar on production. }\end{array}$ \\
\hline 11 & & $\begin{array}{l}\text { Test data juga masih banyak mengandung kelemahan, } \\
\text { dalam arti belum tentu dapat menentukan apakah } \\
\text { program betul-betul sudah error-free (no bug). }\end{array}$ \\
\hline
\end{tabular}


Dari Tabel 1, terlihat bahwa terdapat 2 jenis kelemahan yang paling menonjol dari teknik sistem data uji, yaitu (1) Walaupun dibuat dengan data generator software, tidak mungkin data dapat mencakup semua kemungkinan kesalahan (all possible errors). Suatu aplikasi sudah kita cek dengan data yang sengaja dibuat salah dan kita sudah yakin bahwa program sudah cukup handal, ternyata tetap ada jenis kesalahan lain yang tidak dapat dideteksi oleh program (ada data salah yang dapat masuk ke file); dan (2) Auditor sulit mengetahui dengan yakin apakah program yang dites memang sudah benar-banar program yang dipergunakan secara operasional atau bukan (sulit untuk mengetahui apakah program merupakan "production version, atau yang development version").

\section{Parallel Simulation/Parallel Test Facility (PTF)}

Teknik pemrosesan secara paralel dilaksanakan dengan "client's data, auditor's software." Maksudnya adalah pelaksanaan pemeriksaan dilakukan terhadap data sesungguhnya (data audit yang di-copy) dan diproses dengan software atau bahkan komputernya auditor. Data real ini sebelumnya diproses seperti kegiatan rutin biasanya yang ada pada komputer audit, selanjutnya data di-copy dan diproses ulang (simulasi proses) pada komputer auditor. Laporan yang dihasilkan pada saat simulasi dibandingkan dengan laporan yang dihasilkan dengan pemrosesan rutin perusahaan. Jika terjadi perbedaan, asumsi perbedaan tersebut menunjukkan bahwa software perusahaan tidak memproses data sesuai dengan spesifikasi yang ada (program auditor yang salah). Program yang dipakai dapat dibandingkan antara auditor controlled copy of the client's program dengan software audit tertentu yang dibuat auditor, komputer mikro atau dengan generalized audit program.

Pada dasarnya, sistem PTF dapat dibedakan dengan 2 cara (Lube, D.P., dan Gualate, 2005), yaitu (1) Parallel simulation. Dalam parallel simulation, auditor akan mengcopy data dan diproses pada komputer auditor, tetapi dengan sistem simulasi ( sistem yang dibuat sendiri oleh auditor dengan spesifikasi yang sama dengan aslinya (yang ada diaudit); dan (2) Parallel processing. Dalam parallel processing, auditor akan meng-copy dan diproses pada komputernya auditor dengan sistem aplikasi yang juga di-copy dari komputernya auditor. Berikut ini dapat digambarkan Sistem Paralel Simulasi (Gambar 3) (Gondodiyoto, S., 2007).

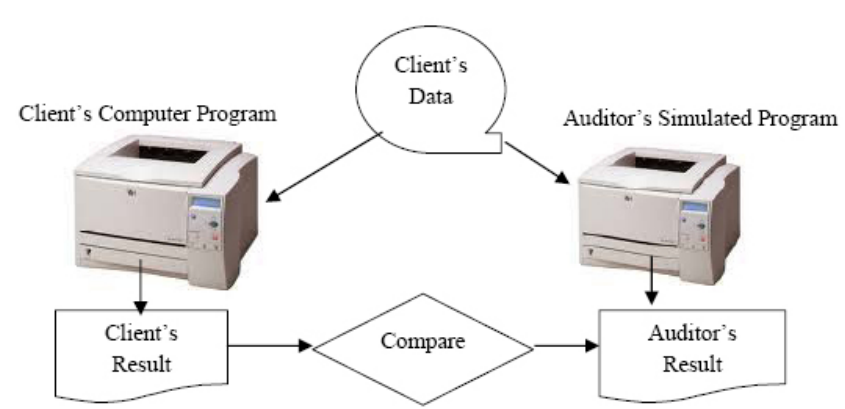

Gambar 3 Sistem Parallel Simulation berikut:

Dari gambar 3, maka dapat dibuat bagan sebagai

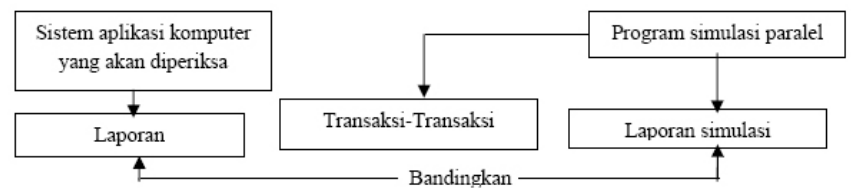

Gambar 4 Parallel Test Facility

Dari Gambar 3 dan 4, terlihat bahwa pada teknik ini mensimulasi proses yang dilaksanakan oleh klien dengan memanfaatkan programnya auditor. Auditor memasukkan data yang sama dengan yang diproses sebelumnya di perusahaan, kemudian real data tersebut diproses dengan program simulasi. Selanjutnya, laporan simulasi dibandingkan dengan laporan yang dihasilkan pemrosesan rutin perusahaan. Jika terjadi perbedaan, maka perbedaan tersebut perlu diteliti penyebabnya. Kelebihan dan kelemahan Parallel Test Facility dapat dilihat pada Tabel 2 (Wilkinson, J.W., 2004).

Berdasarkan Tabel 2, kelemahan PTF ini dapat ditanggulangi dengan membatasi segmen program, misalnya hanya bagian program aplikasi aktiva tetap yang menghitung penyusutan. Pendekatan pelaksaan audit dengan Computer Assisted Audit Techniques (CAATs) dapat dilihat pada Tabel 3.

Tabel 2 Kelebihan dan Kekurangan Parallel Test Facility

\begin{tabular}{|c|c|c|}
\hline No & Kelebihan & Kelemahan \\
\hline 1 & $\begin{array}{l}\text { Teknik ini memeriksa akurasi pemrosesan } \\
\text { dari program aplikasi }\end{array}$ & $\begin{array}{l}\text { Program yang akan dipakai simulasi oleh auditor } \\
\text { perlu dibuat lebih dahulu dan mungkin memakan } \\
\text { waktu dan biaya yang mahal. }\end{array}$ \\
\hline 2 & $\begin{array}{l}\text { Memungkinkan pensalinan output } \\
\text { sesungguhnya }\end{array}$ & $\begin{array}{l}\text { Auditor harus memiliki keahlian komputer yang } \\
\text { cukup kompeten untuk dapat menelusuri kembali } \\
\text { perbedaan antara dua hasil ouput program tersebut. }\end{array}$ \\
\hline 3 & $\begin{array}{l}\text { Cocok untuk pengujian substansif maupun } \\
\text { untuk compliance test }\end{array}$ & $\begin{array}{l}\text { Perlu waktu untuk pengembangan sistem aplikasi } \\
\text { untuk paralelnya. }\end{array}$ \\
\hline 4 & $\begin{array}{l}\text { Audit dilakukan pada komputernya auditor/ } \\
\text { komputer lain/bukan yang sedang diaudit } \\
\text { sehingga diperoleh keyakinan akan status } \\
\text { sistem komputerisasi tersebut dengan lebih } \\
\text { akurat. }\end{array}$ & $\begin{array}{l}\text { Apabila peusahaan meng-update program ada saat } \\
\text { diperiksa tidak segera diketahui dan atau auditor juga } \\
\text { harus segera meng-update programnya. }\end{array}$ \\
\hline 5 & $\begin{array}{l}\text { Auditor dapat memperoleh keyakinan lebih } \\
\text { tinggi karena dengan sistem simulasi kalau } \\
\text { ada hal-hal yang tidak dapat terdeteksi } \\
\text { dengan uji coba saja, maka akan diketahui } \\
\text { karena dicoba dengan sistem yang lain }\end{array}$ & $\begin{array}{l}\text { Expensive to develop generalized audit software } \\
\text { which adequately simulates the client's software. }\end{array}$ \\
\hline
\end{tabular}


Tidak terjadi kontaminasi file klien (does not contaminate client files)
If you should choose to use the client's hardware, the EDP personnel can override the audit software by making modifications to the operating system, especially if they know when you will be running the program.

\begin{tabular}{cll}
\hline 7 & $\begin{array}{l}\text { Proses dapat dilakukan dengan komputer } \\
\text { pihak ketiga yang independen (can be run at } \\
\text { a service bureau independently of client) }\end{array}$ & Diperlukan komputer lain untuk pemeriksaan. \\
\hline 8 & $\begin{array}{l}\text { Auditor menggunakan data klien yang } \\
\text { sebenarnya (real data) }\end{array}$ & $\begin{array}{l}\text { Pada parallel simulation, auditor harus membuat } \\
\text { sistem simulasinya. }\end{array}$ \\
\hline 9 & $\begin{array}{l}\text { Memungkinkan auditor bekerja secara } \\
\text { terpisah dari personil (teknisi) klien sehingga } \\
\text { pelaksanaan audit lebih fleksibel }\end{array}$ & $\begin{array}{l}\text { Audit secata parallel simulation sebenarnya seperti } \\
\text { audit around the computer karena yang diaudit data } \\
\text { (substantive in nature), bukan sistemnya. Karena } \\
\text { tesnya dengan sistem simulasi, maka data yang dicek. }\end{array}$
\end{tabular}

Tabel 3 Teknik Audit Berbantuan Komputer

\begin{tabular}{cll}
\hline Teknik & \multicolumn{1}{c}{ Uraian } & \multicolumn{1}{c}{ Contoh } \\
\hline \multirow{2}{*}{ Data uji } & $\begin{array}{l}\text { Data uji dientri untuk data } \\
\text { yang absah dan yang tidak } \\
\text { absah }\end{array}$ & $\begin{array}{l}\text { Transaksi-transaksi } \\
\text { penggajian yang nomor } \\
\text { identifikasinya absah/tidak } \\
\text { abash }\end{array}$ \\
\hline \multirow{2}{*}{ Simulasi paralel } & $\begin{array}{l}\text { Pemrosesan data nyata } \\
\text { melalui program audit. } \\
\text { Keluaran simulasi dan } \\
\text { keluaran nyata kemudian } \\
\text { dibandingkan }\end{array}$ & $\begin{array}{l}\text { Perhitungan penyusutan } \\
\text { diverifikasi melalui } \\
\text { pemrosesan file master aktiva } \\
\text { tetap dengan program audit. }\end{array}$ \\
\hline
\end{tabular}

\section{SIMPULAN}

Manfaat dukungan komputer selain dirasakan oleh para auditor, manfaat lainnya juga dirasakan oleh manajemen fungsi. Pendekatan audit dalam penyajian financial report dengan menggunakan sistem CAATs sangat bermanfaat untuk metode audit dalam pengujian subtantif atas file/ data/record perusahaan. Software audit yang digunakan CAATs merupakan program komputer yang digunakan oleh auditor untuk membantu pengujian dan evaluasi keandalan file perusahaan (substantive test). Dengan sistem berbasis komputer (CAATs), auditor harus mempertimbangkan teknik-teknik bantuan komputer dalam pelaksanaan audit. Pendekatan CAATs antara lain dengan menggunakan pendekatan data uji dan parallel simulation.

\section{DAFTAR PUSTAKA}

Cangemi, M.P., and Singleton, T. (2002). Managing the audit function a corporate audit department procedures guide, $3^{\text {rd }}$ ed., John Wiley and Sons, Inc.

Gondodiyoto, S., Hendarti, H., dan Ariefah. (2007). Pengelolaan fungsi audit sistem informasi: Contoh audit charter, Jakarta: Mitra Wacana Media.

Gondodiyoto, S. (2007). Audit sistem informasi + pendekatan CobIT, Jakarta: Mitra Wacana Media.

Hall, J.A. (2001). Sistem indormasi akuntansi, buku pertama, edisi pertama. Diterjemahkan oleh Jusuf, A.A., Jakarta: Salemba Empat.

Ikatan Akuntansi Indonesia. (1999). Standar akuntansi keuangan, Jakarta: Salemba Empat.

ISCA. (2005). IS auditing standards, guideline, and procedures for auditing and control professionals.

Lube, D.P., and Gualate. (2005). Auditing information systems audit and assurance, New Delhi: McGrow-Hill Company, Ltd.
Liang, D., F. Lin and S. Wu. (2001). Electronically auditing EDP system with the support of emerging information technologies. International Journal of Accounting Information System. June, $2,130-147$

Romney, M.B., and Steinbart, P.J. (2005). Accounting information system, $10^{\text {th }}$ ed., USA: Prentice-Hall, Inc.

Wilkinson, J.W. (2004). Audit sistem informasi, edisi kedua, Jakarta: Erlangga. 